European Conference on Laboratory Astrophysics - ECLA

C. Stehlé, C. Joblin and L. d'Hendecourt (eds)

EAS Publications Series, 58 (2012) 337-341

www.eas.org

\title{
THERMAL EVOLUTION OF INTERSTELLAR ICE ANALOGUES CONTAINING FORMALDEHYDE
}

\author{
V. Vinogradoff ${ }^{1}$, F. Duvernay ${ }^{1}$, G. Danger ${ }^{1}$, P. Theulé ${ }^{1}$ and T. Chiavassa
}

\begin{abstract}
We have developed a new laboratory approach to investigate the evolution of interstellar ices by separating thermal processing from VUV processing. Infrared spectroscopy and mass spectrometry are used to monitor the thermal evolution of ice containing formaldehyde $\left(\mathrm{H}_{2} \mathrm{CO}\right)$ and ammonia $\left(\mathrm{NH}_{3}\right)$. The main idea is to distinguish photon-induced chemistry from thermally induced chemistry. We show that $\mathrm{H}_{2} \mathrm{CO}$ and $\mathrm{NH}_{3}$ thermally react at low temperature $(40 \mathrm{~K})$ to give aminomethanol $\left(\mathrm{NH}_{2} \mathrm{CH}_{2} \mathrm{OH}\right)$. We also show that in presence of $\mathrm{HCOOH}$ the warming of an ice mixture $\mathrm{H}_{2} \mathrm{CO}: \mathrm{NH}_{3}$ gives at room temperature hexamethylenetetramine $\left(\mathrm{HMT}-\mathrm{C}_{6} \mathrm{H}_{12} \mathrm{~N}_{4}\right)$. From an astrobiological point of view, HMT is of significant interest, since its hydrolysis leads to the formation of amino-acids. Furthermore, it is one of the main refractory products obtained after VUV photolysis at $10 \mathrm{~K}$ of ice mixtures containing $\mathrm{CH}_{3} \mathrm{OH}$ and $\mathrm{NH}_{3}$. It is also suspected to be a part of the organic matter present in comets and asteroids. In this contribution, we demonstrate that HMT can no longer be considered as a reliable indicator of VUV photolysis of ice, as we demonstrate that it can be formed from a purely thermal reaction.
\end{abstract}

\section{Introduction}

Dust grains in the interstellar medium (ISM) play an important role in the chemistry of dense molecular clouds by providing a catalytic surface on which atoms and molecules can stick, forming icy mantles. Dense molecular clouds are characterized by low temperature $(10-50 \mathrm{~K})$ and are the sites of star formation. Part of a dense molecular cloud can collapse gravitationally leading to the formation of a star and subsequently a protoplanetary disk from which planets, asteroids and comets will be formed. During this evolution, organic materials within the icy mantle undergo chemical reactions induced by thermal processes, ultraviolet photons, electron scattering and cosmic rays bombardment, hence increasing the

\footnotetext{
${ }^{1}$ Aix-Marseille Université, Laboratoire de Physique des Interactions Ioniques et Moléculaires, Centre de St-Jérôme, Avenue Escadrille Normandie-Niemen, 13397 Marseille, France
} 
molecular complexity in ices. Those newly formed molecules can be further incorporated in precometary ices. Among molecules that are detected in interstellar ices, we focus our study on formaldehyde $\left(\mathrm{H}_{2} \mathrm{CO}\right)$ and ammonia $\left(\mathrm{NH}_{3}\right)$ which are known constituents of the interstellar icy mantles. Those molecules have been detected in varying proportions from one molecular cloud to another (Dartois 2005), but are around a few percent with respect to $\mathrm{H}_{2} \mathrm{O}$. The $\mathrm{H}_{2} \mathrm{CO}$ molecule is suspected to be formed on the interstellar grains through hydrogenation processes of CO (Watanabe et al. 2004). Thermally promoted formaldehyde reactions at low temperature in $\mathrm{H}_{2} \mathrm{O}: \mathrm{NH}_{3}: \mathrm{H}_{2} \mathrm{CO}$ ices have been previously studied by Schutte et al. (1993a,b). They distinguishes three different products: polyoxymethylene (POM) $\mathrm{OH}\left(\mathrm{CH}_{2} \mathrm{O}\right)_{n} \mathrm{H}$, the $\mathrm{H}_{2} \mathrm{CO}$ polymer, and two other unassigned ones, called $\mathrm{X}$ and $\mathrm{Y}$. The nature of the products and their relative abundances depend strongly on the initial composition of the initial ice mixture. In this contribution, we used infrared spectroscopy and mass spectrometry to monitor the thermal evolution of ice containing formaldehyde $\left(\mathrm{H}_{2} \mathrm{CO}\right)$ and ammonia $\left(\mathrm{NH}_{3}\right)$ to determine the nature of the X product in Schutte's study. We show that $\mathrm{H}_{2} \mathrm{CO}$ and ammonia thermally react at low temperature $(40 \mathrm{~K})$ giving aminomethanol $\left(\mathrm{NH}_{2} \mathrm{CH}_{2} \mathrm{OH}\right)$. We also show that in presence of $\mathrm{HCOOH}$ the warming of an ice mixture $\mathrm{H}_{2} \mathrm{CO}: \mathrm{NH}_{3}$ gives at room temperature hexamethylenetetramine $\left(\mathrm{HMT}-\mathrm{C}_{6} \mathrm{H}_{12} \mathrm{~N}_{4}\right)$. HMT is of significant interest from an astrobiological point of view as its hydrolysis leads to amino-acids, and it seems to be one of the main refractory products obtained after VUV photolysis of ice mixtures containing $\mathrm{CH}_{3} \mathrm{OH}$ and $\mathrm{NH}_{3}$. In addition, we show that HMT can no longer be considered as a reliable indicator of VUV photolysis of ice as we demonstrate that it can be formed from a purely thermal reaction.

\section{Results}

\section{$2.1 \mathrm{NH}_{2} \mathrm{CH}_{2} \mathrm{OH}$ formation from a $\mathrm{H}_{2} \mathrm{O}: \mathrm{NH}_{3}: \mathrm{H}_{2} \mathrm{CO}$ ice mixture}

Thermally promoted formaldehyde reactions at low temperature in $\mathrm{H}_{2} \mathrm{O}: \mathrm{NH}_{3}: \mathrm{H}_{2} \mathrm{CO}$ ices have been studied by Schutte et al. $(1993 \mathrm{a}, \mathrm{b})$. They have shown that $\mathrm{X}$ is the dominant product when $\mathrm{NH}_{3}$ is in excess with respect to $\mathrm{H}_{2} \mathrm{CO}$. In order to produce the $\mathrm{X}$ product only, we start with a $\mathrm{H}_{2} \mathrm{O}: \mathrm{NH}_{3}: \mathrm{H}_{2} \mathrm{CO}$ ice mixture where $\mathrm{NH}_{3}$ is in excess with respect to $\mathrm{H}_{2} \mathrm{CO}$. Figure 1 shows the thermal evolution of a $\mathrm{H}_{2} \mathrm{O}: \mathrm{NH}_{3}: \mathrm{H}_{2} \mathrm{CO}$ ice mixture in a 10:5:0.3 ratio deposited at $10 \mathrm{~K}$. At $10 \mathrm{~K}$ the spectrum is dominated by strong water absorption bands at 3225, 1628 and $790 \mathrm{~cm}^{-1}$, assigned to the $\mathrm{OH}$ stretching mode, $\mathrm{OH}$ bending mode and libration mode respectively. Formaldehyde is characterized by two strong bands located at 1725 and $1492 \mathrm{~cm}^{-1}$ assigned to the $\mathrm{C}=\mathrm{O}$ stretching mode and $\mathrm{CH}$ bending mode respectively. Finally, ammonia is characterized by its strong band at $1110 \mathrm{~cm}^{-1}$ assigned to the inversion mode. Ammonia hydrate $\mathrm{NH}_{3}:\left(\mathrm{H}_{2} \mathrm{O}\right)_{n}$ bands are also observed at $2900 \mathrm{~cm}^{-1}$. During the warming of this ice mixture, above $80 \mathrm{~K}$, new bands are observed at 1390 and $1003 \mathrm{~cm}^{-1}$ while the bands corresponding to $\mathrm{NH}_{3}$ and $\mathrm{H}_{2} \mathrm{CO}$ decrease as it can be seen in Figure 1. The new features are growing until $\mathrm{H}_{2} \mathrm{CO}$ is all consumed. This indicates that a new species is formed by the reaction involving $\mathrm{H}_{2} \mathrm{CO}$ and $\mathrm{NH}_{3}$ during the warming. At $200 \mathrm{~K}$ all the 


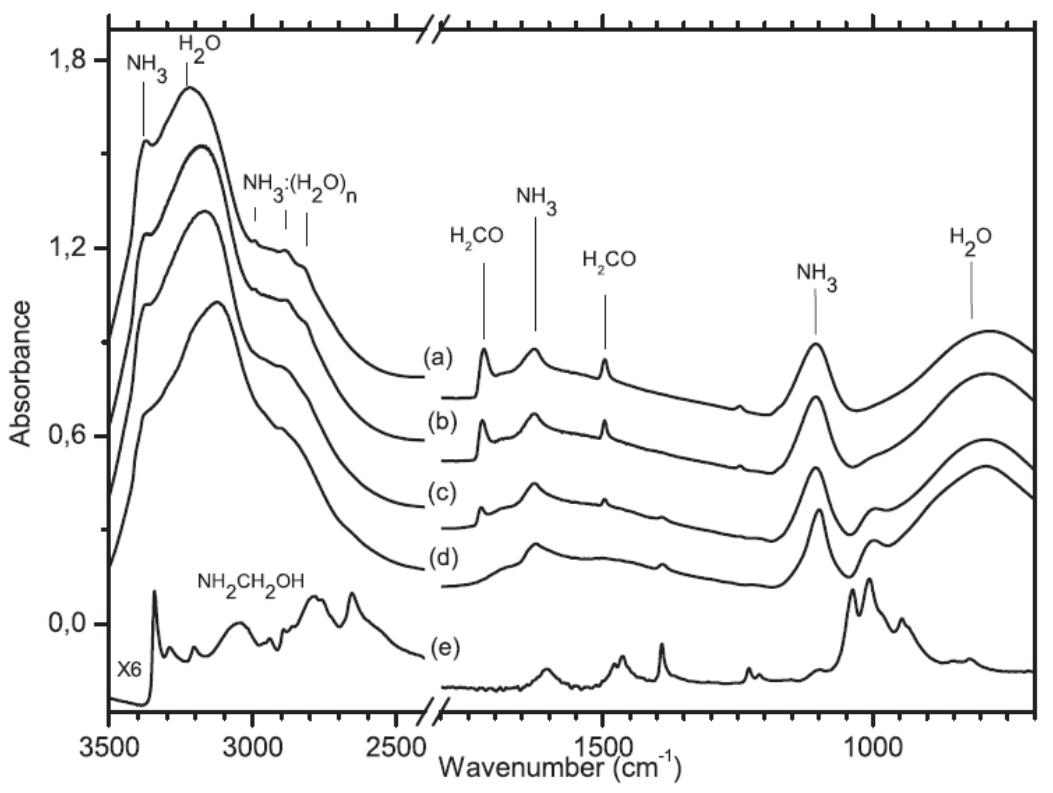

Fig. 1. FTIR spectra of a $\mathrm{H}_{2} \mathrm{O}: \mathrm{NH}_{3}: \mathrm{H}_{2} \mathrm{CO}$ ice mixture in a 10:5:0.3 concentration ratio at (a) $10 \mathrm{~K}$, (b) $90 \mathrm{~K}$, (c) $110 \mathrm{~K}$, (d) $150 \mathrm{~K}$, (e) $200 \mathrm{~K}$.

reactants evaporate, and only an organic residue remains on the substrate. This organic residue fully evaporates at $220 \mathrm{~K}$. Its infrared spectrum, Figure 1, reveals the presence of: an $\mathrm{NH}_{2}$ group from the bands located at 3346 and $3200 \mathrm{~cm}^{-1}$, an $\mathrm{OH}$ group from the broad band at $3051 \mathrm{~cm}^{-1}$, a $\mathrm{CH}$ group from the bands at 2940, 2850, $1390 \mathrm{~cm}^{-1}$ and a C-O group from the band at $1000 \mathrm{~cm}^{-1}$. These bands are characteristic of aminomethanol. This assignment has been confirmed by both B3LYP calculation and mass spectrometry (Bossa et al. 2009). In addition, a kinetic study of the thermal formation of aminomethanol allows us to derive a $4.5 \mathrm{~kJ} . \mathrm{mol}^{-1}$ activation energy for the aminomethanol (Bossa et al. 2009). This very low activation barrier allows aminomethanol formation in interstellar ices, even at very low temperature $(20 \mathrm{~K})$.

\subsection{Thermal formation of HMT}

Figure 2 shows the thermal evolution of a $\mathrm{H}_{2} \mathrm{CO}: \mathrm{NH}_{3}: \mathrm{HCOOH}$ ice mixture in a 1:6:1 concentration ratio from $15 \mathrm{~K}$ to $330 \mathrm{~K}$. At $15 \mathrm{~K}$, the $\mathrm{IR}$ spectrum is dominated by a strong feature at $1585 \mathrm{~cm}^{-1}$ assigned to $\mathrm{HCOO}^{-}$. Indeed, the ammonium formate $\mathrm{HCOO}^{-} \mathrm{NH}_{4}^{+}$is formed at low temperature $(\mathrm{T}<40 \mathrm{~K})$ from $\mathrm{HCOOH}$ and $\mathrm{NH}_{3}$ (Schutte et al. 1999). After the disappearance of the reactants $\left(\mathrm{H}_{2} \mathrm{CO}, \mathrm{NH}_{3}\right.$, and $\left.\mathrm{HCOOH}\right)$, at $220 \mathrm{~K}$ the IR spectrum is the addition of ammonium formate and aminomethanol infrared spectra. At $330 \mathrm{~K}$, the organic residue is easily assigned to HMT from its IR bands located at 1007 , and $1235 \mathrm{~cm}^{-1}$ (Fig. 2). Here the HMT is formed without any photon, just by thermal activation. 


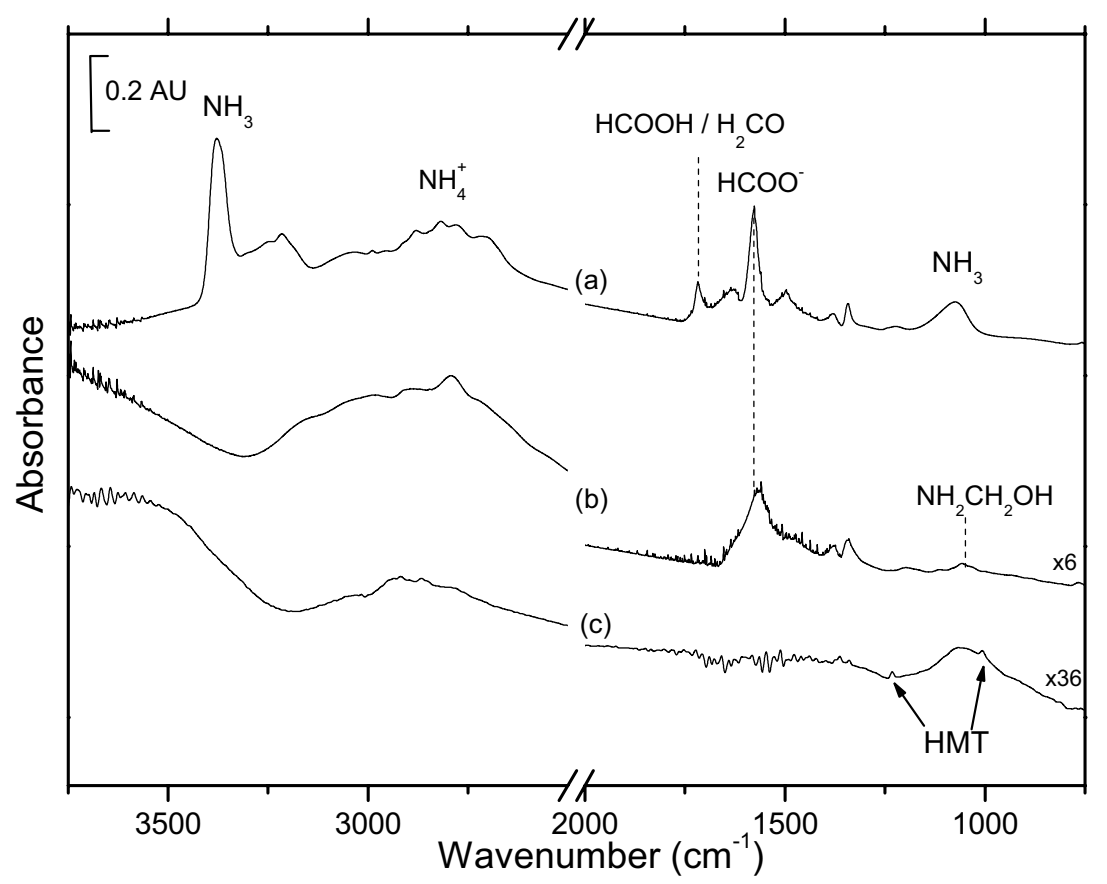

Fig. 2. FTIR spectrum of $\mathrm{H}_{2} \mathrm{CO}: \mathrm{NH}_{3}: \mathrm{HCOOH}$ ice mixture in a 1:6:1 concentration ratio at (a) $15 \mathrm{~K}$, (b) $220 \mathrm{~K}$, (c) $330 \mathrm{~K}$.

It is worth noticing that if $\mathrm{HCOOH}$ is not present in the ice-mixture, no HMT is observed (Bossa et al. 2009).

From the infrared spectrum, it is difficult to define at which temperature HMT is formed because of spectral confusion with $\mathrm{NH}_{3}$ and aminomethanol bands. Based on the infrared spectrum, HMT does not seem to form immediately when room temperature is reached. At $300 \mathrm{~K}$, only the $\mathrm{HCOO}^{-}$feature is observed at $1585 \mathrm{~cm}^{-1}$. The HMT features are gradually formed as the temperature increases from 300 to $330 \mathrm{~K}$ while the $\mathrm{HCOO}^{-}$feature located at $1585 \mathrm{~cm}^{-1}$ decreases. Consequently, HMT seems to form only at the final stage of the experiment (i.e. 300-330 K). This result has been already observed during the warming of a photolysed-ice with methanol and ammonia (Bernstein et al. 1997; Muñoz Caro \& Schutte 2003). Those results clearly show the existence in ices of a stable intermediate between $200 \mathrm{~K}$ and $300 \mathrm{~K}$, that leads to the formation of HMT, but only at a temperature higher than $300 \mathrm{~K}$. So far the nature of this intermediate is still unknown but it is under further investigations.

\section{Conclusion}

Our experiments have shown that in the solid phase, $\mathrm{H}_{2} \mathrm{CO}: \mathrm{NH}_{3}$ ice mixtures efficiently generate new organic molecules when warmed to room temperature. The 


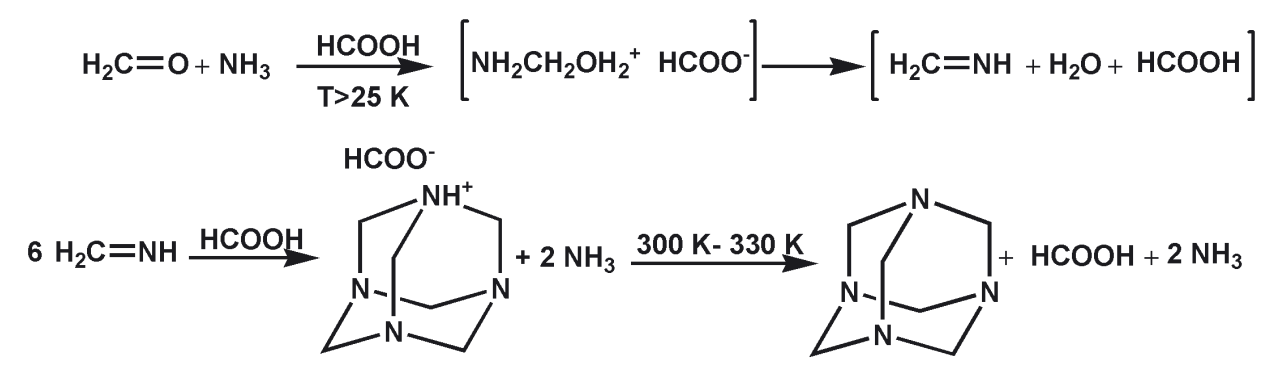

Fig. 3. New mechanism for HMT formation in astrophysical ice analogs.

nature of the residue depends on the initial ice composition. If formaldehyde is in excess with respect to ammonia, POM is the main residue, while when ammonia is in excess with respect to formaldehyde, HMT is the main product as long as $\mathrm{HCOOH}$ is present in the ice mixture. Comparison with previous studies have been made and demonstrate that formaldehyde containing ice is a better precursors for HMT production than methanol containing ice (Vinogradoff et al. 2011). We also demonstrate for the first time that HMT can be formed thermally in interstellar ice analogs $\mathrm{H}_{2} \mathrm{CO}: \mathrm{NH}_{3}: \mathrm{HCOOH}$, without any energetic processing (photons or energetics particles). The presence of $\mathrm{HCOOH}$ is crutial for HMT formation as it catalyzes methylenimine $\left(\mathrm{CH}_{2}=\mathrm{NH}\right)$ formation from aminomethanol $\left(\mathrm{NH}_{2} \mathrm{CH}_{2} \mathrm{OH}\right)$ dehydration (Fig. 3).

Hence, We conclude that HMT cannot be considered anymore as a good indicator of VUV photolysis of interstellar ices. These results also show that HMT could be present in some thermally processed astrophysical environments, such as comet cores. That why, the presence of HMT in cometary core is usually presented as a possible candidate of HCN extended sources observed in comets (Fray et al. 2004).

\section{References}

Bernstein, M., Allamandola, L., \& Sandford, S., 1997, Adv. Space Res., 19, 991

Bossa, J., Theule, P., Duvernay, F., \& Chiavassa, T., 2009, ApJ, 707, 1524

Dartois, E., 2005, ISO Science Legacy, 293

Fray, N., Bénilan, Y., Cottin, H., et al., 2004, Meteor. Planet. Sci., 39, 581

Muñoz Caro, G., \& Schutte, W., 2003, A\&A, 412, 121

Schutte, W., Allamandola, L., \& Sandford, S., 1993a, Icarus, 104, 118

Schutte, W., Allamandola, L., \& Sandford, S., 1993b, Science, 259, 1143

Schutte, W., Boogert, A., Tielens, A., et al., 1999, A\&A, 343, 966

Vinogradoff, V., Duvernay, F., Danger, G., Theulé, P., \& Chiavassa, T., 2011, A\&A, 530

Watanabe, N., Nagaoka, A., Shiraki, T., \& Kouchi, A., 2004, ApJ, 616, 638 